\title{
Investigating the Appropriateness of Reading Passages of Grade Seven English Textbook: Tsehay Chora Primary School in Focus, Addis Ababa, Ethiopia
}

\author{
Simachew Gashaye \\ Debre Markos University, Debre Makos, Ethiopia \\ Manyazewal Girma \\ Debre Markos University, Debre Makos, Ethiopia
}

\begin{abstract}
The purpose of this study was to assess the appropriateness of reading passages of Grade Seven English textbook suitability in developing students' reading comprehension Descriptive research design with both qualitative and quantitative research methods were employed. In the study, 42 Grade Seven students randomly and four English language teachers with comprehensive sampling technique were included. The instruments used to collect data were document analysis, students' questionnaire, and teachers' interview. The data gathered through document analyses and students' questionnaires were analyzed with frequency, percentages and mean; whereas, teachers' interview data were analyzed through narration. The finding of study showed that, the reading passages of the current Grade Seven English textbook lack interestingness, authenticity and sufficient vocabulary. These deficiencies could hamper the appropriateness of reading passages so that the reading texts could not be adequate to develop the students' reading skills. Hence, the reading passages should be revised to be appropriate for students' success in reading.
\end{abstract}

Index Terms -illustration, vocabulary sufficiency, authenticity, cultural appropriateness, and interestingness

\section{INTRODUCTION}

Textbooks play a vital role in teaching English because they form the fundamental of language input learners acquire in the classroom (Kirkgoz, 2009). Because of this, it is necessary to evaluate the appropriateness of the textbooks to meet the desired learning outcomes. The process of evaluating and selecting textbooks is of course complex, and it involves different stakeholders such as curriculum designers, teachers and learners. The selected textbooks should meet the need of learners as different writers suggest (Judy, 2007). Therefore, textbook evaluation covers the contents, activities, illustrations, objectives, authenticity of the language, difficulty level of tasks and cultural appropriateness of the lessons given in the textbook.

In this regard, Raval (2013) argues that appropriateness of English textbook and the reading passages in the textbook play important role in students' language learning. Due to this fact appropriate reading passages in the textbook should include suitable contents, vocabulary, structures, and proportion in exercise, glossary and illustration that go with the title of the reading passages. The reading of pictures is not just a different process from that of reading of words, but can be a process that is equally as complex as that of reading words (Judy, 2007).

Using illustrations as a reading tool offers a powerful medium to those who are involved in the literacy development of emergent readers. Sheldon (1988) elaborates that one picture may be worth a thousand words and it serve as functional as simply decorative and clear for their intended purpose. Thus, the use of illustrations for the reading purpose has paramount value that it could make the students motivated, provide meaningful context and help them to understand reading comprehension in terms of the printed word.

Reading passages should also contain interesting reading topics. Williams (1986) claims that in the absence of interesting texts, very little is possible.' Jordan (1997) supplementing this notes that interest is vital, for it increases motivation in the development of reading speed and fluency. When the topic of a passage is not interesting for students, their motivation to read is substantially lessened.

Authenticity in language use is crucial in reading in order to introduce students to the real context and natural instances of language. Therefore, authentic materials in the reading passages inspire students to read passages interestingly (Ali, 2010).

Cultural relatedness of the reading texts is the other important aspect. Brown (1994) points out that culture is the context within which we exist, think, feel and relate others. It is the glue that binds a group of people together. It can be defined as a blueprint that guides the behavior of people in community and is incubated in family life. Consequently, 
the reading passages that are not related to the students' culture and religion may be less motivating for them to read and will be more difficult to comprehend than the culturally-related ones.

Moreover, for the appropriateness reading passages vocabulary is an important aspect to be considered. As (McDonough et.al, 2013) cited in (Getinet, 2018) argue that knowledge of vocabulary is often considered to be an integral part of a reader's overall competence in foreign or second languages. That is knowledge of vocabulary in a foreign language is considered to be very essential for readers.

In addition to the above scholars ideas the researchers have also consulted studies done elsewhere out of Ethiopia. For instance, Ali (2010) studied on evaluation of the reading text and exercise of Palestine - Grade 9. The result indicates that no authentic reading texts are found in the textbook. Moreover, extensive reading is not included. Yee Chiew (2012) examined the extent to which the textbook used in the university-based intensive English program matches with the set of criteria for selecting a good reading textbook. Findings from this study suggest that the textbook conforms to all the four important criteria of reading textbook selection. It can be concluded that the textbook is appropriate for students reading literacy development. Further research could be done on the aspect of authentic text presentation which has been overlooked by the present study.

In addition, Rahma, (2004) evaluated the teaching of reading skills of English in Bangladesh. The findings show that students' present level of reading is not up to the mark because of insufficient vocabulary found in the reading passages. Therefore, the above study revealed that insufficient vocabulary found in reading passages was the problems for students' to develop the reading skills.

The current study focused on investigating the appropriateness of reading passages against the criteria stated above; namely, illustration, interestingness, authenticity, cultural appropriateness and vocabulary knowledge. As mentioned in the Education and Training Policy of Ministry of Education (MoE, (2007) of Ethiopia states English is taught as a subject from Grade One, and it is the medium of instruction from Grade Nine through high school, colleges and universities. For each grade level, the teachers and the students use textbooks prepared by MoE. However, the illustration, the vocabulary items found in the passages might not be suitable for the learners.

\section{A. Statement of the Problem}

English is one of the foreign languages that have been used in Ethiopia since the introduction of modern education in the early 20th century. Since then both governmental and non-governmental schools played significant roles in the spread of English language education in Ethiopian (MoE,2007).As a result of this, Ethiopia has introduced English language to be a compulsory subject and the language of instruction starting from Grade Seven up to university education.

Currently, communicative approach language has been employed I English language teaching in all levels of the education system of Ethiopia. All the materials used by teachers and students are printed in the English language. Therefore, students' especially primary school level ones are supposed to master the skills in English language.

Among these four major skills, reading is considered as one of the most important receptive skills which language learners should master. Reading cannot be considered as a set of mechanical skills to be learned once and for all but rather it is a complex process of making meaning from passages for a variety of purposes (Lyon, 2003).

The objective of teaching reading skills in Grade Seven like other grades is to develop students' reading comprehension ability in English language, Institute for Curriculum Development and Research (ICDR, 2004). To accomplish this objective, different reading passages were designed and incorporated in the English language syllabus. However, as it has been mentioned by some researchers, students' proficiency in the English language was not as expected. Our experience at Tsehay Chora Primary School shows that students' reading ability tends to be poor. In addition to this, Ethiopian Early Grade Reading Assessment (EGRA, 2010) showed that there is strong evidence that reading achievement is low in all regions. Most critically, these findings showed that reading achievement is very low in Ethiopia. When students were asked to read a simple passage at Grade 2 and Grade 3 levels, more than 50\% of the children in most regions were unable to answer a single simple comprehension question. This may be due to the inappropriateness of the reading passages of the textbook for their language learning.

To mention other local research, for instance, Getinet (2018) conducted study on evaluating the appropriateness of Grade Nine English reading texts from the perspective of teachers and students. He evaluated the textbook by using certain criteria like the readability, exploitability, socio- cultural content and students' background from the perspective of teachers and students. But, he did not investigate the appropriateness of reading passages by using certain criteria such as illustration, interestingness, authenticity, cultural appropriateness, and lexical knowledge.

Therefore, the purpose of this study was to investigate the appropriateness of the reading passages of Grade Seven English textbook.

\section{B. Research Questions}

The study attempted to answer the following research questions.

1. Does textbook contain the reading passages that have clear illustrations?

2. Does the textbook contain interesting reading passages?

3. Does the textbook contain authentic reading passages?

4. Does the textbook contain culturally appropriate reading passages? 
5. Does the textbook contain enough vocabulary for students?

\section{Methodology}

The study employed descriptive research design by using mixed methods data collection and analysis methods.

\section{A. Participants of the Study and Sampling Techniques}

The study was conducted at Tsehay Chora Primary School which, Addis Ababa, Ethiopia. The participants of this study were Grade Seven students and their English language teachers. There were 140 students in four sections (A, B, C and D) in the 2018/19 academic year. Taking 30 percent of the students randomly through lottery system from each section, eleven (totally, 44) students were selected. Besides, using comprehensive sampling technique, four English language teachers who teach in both Grades Seven and Eight were included. Moreover, 14 reading passages were taken from Grade Seven English textbook though comprehensive sampling technique.

\section{B. Data Gathering Instrument}

By employing mixed-methods research approach, data were collected through document analysis, student questionnaire and teachers' interview.

Document analysis was used to examine the appropriateness of the reading passages. To assess the reading texts, criteria were developed through adapting Ali (2010) and Cunningsworth (1995) works. Specifically, the parameters used as a check list to examine the passages were illustration, interestingness, authenticity, cultural appropriateness and vocabulary. The checklist prepared was Yes/No format. The scope of the document analysis is limited only to the reading passages that are presented in the textbook with the view of supporting students' comprehension skill.

Questionnaire was administered to assess students' views about appropriateness of the reading texts in relation to illustration, interestingness and cultural appropriateness. The questionnaire items were closed- ended in form having five level Likert scale that range from 'strongly disagree' to 'strongly agree'. The items were translated into Amharic for students' easy understanding.

The four teachers were interviewed about the appropriateness of the reading passages for their students. The interview items were semi-structured in form enquiring the appropriateness of the reading passages in terms of their authenticity and cultural relatedness to their students.

\section{Data Analysis Techniques}

The data gathered through documents analysis and students' questioner were analyzed and interpreted quantitatively by using, frequency, percentage, mean, and grand mean; whereas, the data obtained from teachers' interview were analysed thematically using narration in the statements.

\section{DATA ANALYSIS AND DisCUSSION OF FINDINGS}

\section{A. Document Analyses}

The Grade Seven English textbook was published in 2011. The textbook contains twelve units in which there is at least one reading passage. Hence, this study focuses on the examining the appropriateness of reading passages for students developing their reading comprehension. The reading passages in the textbook were evaluated by adapting the criteria developed by Ali (2010) and Cunning (1995).

The document analysis was made under five major themes in line with the set research questions. They are clarity of illustrations, interestingness of reading passages, authenticity of the passages, cultural appropriateness of reading passages and sufficiency of vocabulary items found in the reading passages. Therefore, the fourteen reading passages of the textbook were evaluated five times with the five themes. Consequently, $(14 \mathrm{x} 5)=70$ was maximum value. Similarly, the research questions numbers two, three and four were grouped into one and each reading passage was evaluated four times. Thus, their minimum value was $56(14 \times 4)=56$ percent. Table 1 summarizes the result obtained from document analysis

TABLE I.

READING PASSAGES ANALYSis With ILLUSTRATION, VOCABUlARY SUFFICIENCY, AUTHENTICITY, INTERESTINGNESS AND CULTURAL APPROPRIATENESS

\begin{tabular}{|c|l|c|c|c|c|c|c|}
\hline \multirow{2}{*}{ No } & \multirow{2}{*}{$\begin{array}{c}\text { Appearance in the 14 } \\
\text { reading passages }\end{array}$} & \multicolumn{6}{|c|}{ Alternatives } \\
\cline { 3 - 8 } & & \multicolumn{2}{|c|}{ Yes } & \multicolumn{2}{c|}{ No } & \multicolumn{2}{c|}{ Total } \\
\cline { 3 - 8 } & & $\mathrm{F}$ & $\%$ & $\mathrm{~F}$ & $\%$ & $\mathrm{~F}$ & $\%$ \\
\hline 1 & Illustration & 40 & 57.1 & 30 & 42.9 & 70 & 100 \\
\hline 2 & Vocabulary & 10 & 27.1 & 51 & 72.9 & 70 & 100 \\
\hline 3 & Authenticity & 20 & 35.7 & 36 & 64.3 & 56 & 100 \\
\hline 4 & Interestingness & 53 & 94.6 & 3 & 5.4 & 56 & 100 \\
\hline 5 & Cultural appropriateness & & & & & & \\
\hline
\end{tabular}

Key $=\mathrm{F}=$ Frequency $\%=$ Percentage 
The above table indicates from the five indicators of passage appropriateness, the analysis shows that cultural appropriateness and illustration were found meeting the criteria. To be specific, cultural appropriateness has the frequency of $53(94.6 \%)$ appearance in the reading passages. The other quality that the passage tended to fit with the purpose of the textbook is the clarity of illustrations which appeared with the frequency of 40 (57.1\%). However, the other qualities of the reading passages tended to lack are authenticity of the passages which is rated as 17.9 percent appearance and sufficiency of vocabulary with the rate of appearance in 27.1 percent.

Therefore, the reading passages though they satisfy the qualities of cultural appropriateness and clear illustrations; they lack to have adequate vocabulary, authenticity, and interestingness.

\section{B. The Students' Questionnaire}

The obtained from 44 students using questionnaire were presented and analysed using percent and mean as follows. First, the data analysis related to clarity of illustration is presented. Then, the analysis data about interestingness of reading passages is reported. Finally, the analysis of the vocabulary found in the textbook is presented.

TABLE II.

ANALYSIS OF CLARITY OF ILLUSTRATION

\begin{tabular}{|c|c|c|c|c|c|c|c|c|c|}
\hline Items & Contents & & 1 & 2 & 3 & 4 & 5 & Total & Mean \\
\hline \multirow[t]{7}{*}{ No 1} & \multirow{2}{*}{$\begin{array}{l}\text { There are adequate illustrations } \\
\text { found in the reading passage. }\end{array}$} & $\mathrm{F}$ & 6 & 6 & 1 & 19 & 10 & 42 & \multirow[t]{2}{*}{3.14} \\
\hline & & $\%$ & 14.3 & 28.6 & 2.4 & 45.6 & 24.2 & 100 & \\
\hline & \multirow{2}{*}{$\begin{array}{l}\text { All the reading passages have clear } \\
\text { illustrations. }\end{array}$} & $\mathrm{F}$ & 6 & 15 & 1 & 5 & 15 & 42 & 3.19 \\
\hline & & $\%$ & 14.3 & 35.7 & 2.4 & 11.9 & 35.7 & 100 & \\
\hline & \multirow{2}{*}{$\begin{array}{l}\text { The reading passages have the visual } \\
\text { imagery of high aesthetic quality. }\end{array}$} & $\mathrm{F}$ & 24 & 13 & 2 & 3 & 0 & 42 & \multirow[t]{2}{*}{1.62} \\
\hline & & $\%$ & 57.1 & 31.0 & 4.8 & 7.1 & 0.0 & 100 & \\
\hline & \multirow{2}{*}{$\begin{array}{l}\text { The illustration found in the reading } \\
\text { passages are relevant }\end{array}$} & $\mathrm{F}$ & 4 & 10 & 2 & 19 & 7 & 42 & \multirow[t]{2}{*}{3.36} \\
\hline \multirow{4}{*}{ Illustration } & & $\%$ & 9.5 & 23.8 & 4.8 & 45.2 & 16.7 & 100 & \\
\hline & \multirow{2}{*}{$\begin{array}{l}\text { The illustrations found in the } \\
\text { reading passages are functional }\end{array}$} & $\mathrm{F}$ & 3 & 10 & 4 & 9 & 16 & 42 & \multirow[t]{2}{*}{3.6} \\
\hline & & $\%$ & 7.1 & 23.8 & 9.5 & 21.4 & 38.1 & 100 & \\
\hline & Grand mean & & & & & & & & 3.98 \\
\hline
\end{tabular}

As Table 2 showed that, most of the respondents agree that illustrations found in the reading passages are adequate, clear, have high aesthetic quality, relevant and functional. It is evident that the grand mean of the analysis obtained is closer to 4.0 which is to mean that respondents agree about the clarity of the illustrations.

The next part of the analysis tries to assess the interestingness of the reading passages for the learners to develop their reading skills. The following table presents students response about the interestingness of the passages.

TABLE III.

ANALYSIS OF INTERESTINGNESS OF READING PASSAGES

\begin{tabular}{|c|c|c|c|c|c|c|c|c|c|}
\hline Items & Contents & & 1 & 2 & 3 & 4 & 5 & Total & Mean \\
\hline \multirow{9}{*}{$\begin{array}{l}\text { No } 2 \\
\text { Interestingness }\end{array}$} & \multirow{2}{*}{$\begin{array}{l}\text { Illustrations } \\
\text { are interesting }\end{array}$} & $\mathrm{F}$ & 22 & 10 & 2 & 6 & 2 & 42 & \multirow[t]{2}{*}{1.95} \\
\hline & & $\%$ & 52.4 & $\begin{array}{l}23 . \\
8\end{array}$ & 4.8 & $\begin{array}{l}14 . \\
3\end{array}$ & 4.8 & 100 & \\
\hline & \multirow[b]{2}{*}{$\begin{array}{l}\text { The reading passages } \\
\text { are } \\
\text { interesting enough } \\
\text { that student enjoy } \\
\text { reading them? }\end{array}$} & $\mathrm{F}$ & 30 & 6 & 2 & 3 & 1 & 42 & \multirow[t]{2}{*}{1.86} \\
\hline & & $\%$ & 71.8 & $\begin{array}{l}14 . \\
3\end{array}$ & 4.8 & 7.1 & 2.4 & 100 & \\
\hline & \multirow[b]{2}{*}{$\begin{array}{l}\text { The reading passage } \\
\text { contain variety of } \\
\text { reading topics that } \\
\text { arise students' } \\
\text { interest }\end{array}$} & $\mathrm{F}$ & 26 & 5 & 2 & 4 & 5 & 42 & \multirow[t]{2}{*}{1.98} \\
\hline & & $\%$ & 61.9 & $\begin{array}{l}11 . \\
9\end{array}$ & 4.8 & 9.5 & 11.9 & 100 & \\
\hline & \multirow{2}{*}{$\begin{array}{l}\text { There are reading } \\
\text { passage that are not } \\
\text { interesting for } \\
\text { students }\end{array}$} & $\mathrm{F}$ & 6 & 12 & 1 & 16 & 7 & 42 & \multirow[t]{2}{*}{3.14} \\
\hline & & $\%$ & 14.3 & $\begin{array}{l}28 . \\
6\end{array}$ & 2.4 & $\begin{array}{l}38 . \\
1\end{array}$ & 16.7 & 100 & \\
\hline & Grand Mean & & & & & & & & 2.23 \\
\hline
\end{tabular}

The interestingness of reading passages found in the textbook appeared to be less as the analysis of the students response revealed in the above table. The mean results of the different indicators for interestingness of reading passages is below the average score in the five levels Likert scale. Besides, the grand mean shows was found to be 2.23 Which still signifies the reading passages that are found in the grade seven English textbook are not interesting for the students.

Finally, the students responses about adequacy of vocabulary in the reading passages was analysed in the following table. The analysis was done using indicators for the sufficiency of vocabulary. The indicators are progression of 
vocabulary from simple to complex, use extra colors to highlight new vocabulary, inclusion of new vocabulary that are concrete and sufficient vocabulary items.

TABLE IV.

ANALYSIS OF SUFFICIENCY OF VOCABULARY IN THE READING PASSAGES

\begin{tabular}{|c|c|c|c|c|c|c|c|c|c|}
\hline Items & Contents & & 1 & 2 & 3 & 4 & 5 & Total & Mean \\
\hline \multirow{11}{*}{$\begin{array}{l}\text { No } 3 \\
\text { Vocabulary }\end{array}$} & \multirow{2}{*}{$\begin{array}{l}\text { The arrangement of } \\
\text { vocabulary items is from } \\
\text { simple to complex }\end{array}$} & $\mathrm{F}$ & 10 & 14 & 5 & 2 & 11 & 42 & \multirow[t]{2}{*}{2.21} \\
\hline & & $\%$ & 23.8 & $\begin{array}{l}33 . \\
3\end{array}$ & $\begin{array}{l}11 . \\
9\end{array}$ & 4.8 & $\begin{array}{l}26 . \\
2\end{array}$ & 100 & \\
\hline & \multirow{2}{*}{$\begin{array}{l}\text { The new words in the reading } \\
\text { passages are highlighted }\end{array}$} & $\mathrm{F}$ & 22 & 4 & 1 & 15 & 0 & 42 & \multirow[t]{2}{*}{2.76} \\
\hline & & $\%$ & 52.4 & 9.5 & 2.4 & 35.7 & 0.0 & 100 & \\
\hline & \multirow{2}{*}{$\begin{array}{l}\text { The reading passages provide } \\
\text { learners with sufficient } \\
\text { vocabulary items }\end{array}$} & $\mathrm{F}$ & 31 & 0 & 1 & 4 & 6 & 42 & \multirow[t]{2}{*}{1.90} \\
\hline & & $\%$ & 73.8 & 0.0 & 2.4 & 9.5 & $\begin{array}{l}14 . \\
3\end{array}$ & 100 & \\
\hline & \multirow{2}{*}{$\begin{array}{l}\text { The pages included } \\
\text { vocabularies that are concrete }\end{array}$} & $\mathrm{F}$ & 17 & 15 & 4 & 2 & 4 & 42 & \multirow[t]{2}{*}{2.07} \\
\hline & & $\%$ & 40.5 & $\begin{array}{l}35 . \\
7\end{array}$ & 9.5 & 4.8 & 9.5 & 100 & \\
\hline & \multirow{2}{*}{$\begin{array}{l}\text { The reading passages use } \\
\text { colors to highlight new words }\end{array}$} & $\mathrm{F}$ & 18 & 12 & 4 & 3 & 5 & 42 & \multirow[t]{2}{*}{2.17} \\
\hline & & $\%$ & 42.9 & $\begin{array}{l}28 . \\
6\end{array}$ & 9.5 & 7.1 & 11 & 100 & \\
\hline & Grand Mean & & & & & & & & 2.22 \\
\hline
\end{tabular}

Table 4 above indicated the analysis students' views about the adequacy of new words in the reading passages using indicators. As the mean result shows the reading passages tend to have less new words to develop students' comprehension ability. The mean result in all the indicators for the sufficiency of vocabulary is below the average score. As a result the grand mean is 2.22 on the five levels Likert scale. This showed that the vocabularies found in the reading passages are not sufficiently presented.

Generally, the result of students' questionnaire analysis shows that the reading passages of the textbook tend to be less interesting and lack adequate vocabulary though it was reported that the passages have clear illustrations. This implies that the passages will not enable students to develop their compression ability.

\section{Teachers Interview}

With the interview, the authenticity and the cultural appropriateness of the reading passages was examined. The analysis of the interview was done thematically. First the analysis teachers' response about the authenticity of the passages is presented. Then, the analysis of the responses about the cultural appropriateness of the passages is reported.

Regarding the authenticity of the reading passages, majority of the respondents agree that the passages lack authenticity. For instance, Teacher ${ }_{1}$ notes that "The reading passages.....are not enriched with authentic reading passages. For example, from the 14 passages 12 of them are not authentic and two of them that is in Unit 3 page 45 and Unit 6 on

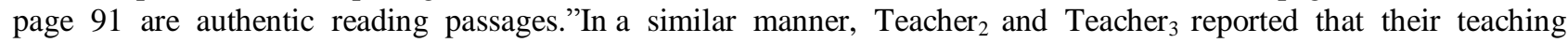
experience for more than eight years showed them that textbook contain non-authentic reading passages. They specifically identified only two passages, namely "Bull Jumping and Cotton Growing" are the only authentic reading passages that expose learners to real life experience.

Hence, from this analysis, it is possible to say that the reading passages are not authentic. This in turn affects students' learning to develop their reading skills in the language.

The analysis of teachers' interview response about cultural appropriateness of the reading passages indicates that most of the reading passages are culturally appropriate. Almost all respondents agreed that the topics of the reading passages are customized to be culturally fit to the students experience and exposure. They mention some of the topics of the passages like "Jumping the Bull, Tsemay and Banna, the Traditional Game Gebet'a, and Growing Cotton".

From the above analysis, it could be concluded that reading passages found in Grade Seven English textbook are culturally appropriate for the learners. This will in turn enhance students' reading skills.

\section{Discussion OF FINDINGS}

The main purpose of this study was to investigate the appropriateness of the reading passages of Grade Seven English textbook. In this section an attempt was made to discuss important findings of the study with related to research objectives.

The first research question was intended to assess if the reading passages of the textbook contain clear illustrations. The findings of the document analysis showed that majority of the reading passages have illustrations. In addition, the result obtained from students' questioner assured the existence of clear illustrations and suitable visual texts in the reading passages. Therefore, this find of this study agrees with what Sheldon (1988) recommends about the importance of illustrations for reading passages.

The second research question examined the interestingness of reading passages. The findings of the document analyses revealed that majority reading passages contains less interesting reading passages. From the 14 reading 
passages, $11(78.5 \%)$ of the reading passages are not interesting reading passages. Besides, the finding from the students' questionnaire analysis still signifies the reading passages that are found in the textbook are not interesting for the students as the grand mean was found to be 2.23 .

The third research question was concerned to examine authenticity of the reading passages. To this end, the result of document analyses revealed that the textbook comprised non-authentic and outdated passages. Similarly, the findings of the teachers' interview data analysis assured that majority of the reading passages in the textbooks include nonauthentic reading passages. From the 12 reading passages $12(85.7 \%)$ of them were non-authentic passage. This finding disagrees with what Cunnings worth (1995), Ur (1996) and Berardo (2006) recommend. They contend that authentic texts can be motivating and more interesting. Also Al-Masri (1993) asserts that the learners are likely to be more motivated by the relevance, usefulness and authenticity of the learning tasks.

The fourth research question was intended to examine the cultural appropriateness of the reading passages. The result of document analyses showed that the reading passages of textbook are culturally appropriate. Similarly, the findings of the teacher interview data analyses assured that almost all the reading passages found in the textbook were culturally appropriate for the students. This finding with what Niederhauser (1997) suggests that bringing culture related content into the language classroom is one of the best ways of increasing motivation.

The last research question was intended to assess the adequacy of vocabulary in the reading passages. In this regard, the findings of the document analyses and students 'questionnaires indicated that there were not enough new vocabulary items in the reading passages. From the fourteen passages only five of them have new vocabulary items. Therefore, it is possible to deduce that the textbook did not help students to develop their guessing and word attack skills which in turn make students have less stock of vocabulary.

\section{CONCLUSION}

The intent of this study was to investigate the appropriateness of reading passages of Grade Seven English textbook. It examined the reading passages in terms of illustration, interestingness, authenticity, cultural appropriateness and sufficiency of vocabulary. The following conclusions were drawn from the findings obtained.

$>$ The reading passages of the textbook had clear illustrations.

$>$ The passages were found less interesting.

$>$ The reading passages were less authentic.

$>$ The passages were found culturally appropriate to the students.

Generally, though the reading passages of Grade Seven English textbook satisfy the criteria of clear illustrations and cultural appropriateness, they lack inclusion of adequate new vocabulary, arise interest of students and authenticity.

Therefore, it is recommended that the Ethiopian Ministry of Education, particularly, Syllabus Designing Department should revise the Grade Seven English textbook reading passages to

$>$ make them more illustrative and culturally fit and

$>$ to improve the deficiencies of the reading passages in availability of new vocabulary, interestingness of the passages and authenticity of passages

\section{ACKNOWLEDGEMENTS}

Our special thanks go to Tsehay Chora Primary School students and teachers who kindly collaborated us during data gathering.

\section{REFERENCES}

[1] Ali, N. (2010). An Evaluation of the Reading Texts \& Exercises in SB \& WB of English for Palestine - Grade 9. Unpublished M.A. Thesis. The Islamic University of Gaza, Gaza.

[2] Al- Masri, N. (1993). Developing Learning Materials for Palestinian Learners of English in Gaza Strip. Unpublished $\mathrm{Ph} . \mathrm{D}$.Thesis, the University of Manchester, UK.

[3] Berardo, S. (2006). The Use of Authentic Materials in the Teaching of Reading. The Reading Matrix, .6 (2), 60-69.

[4] Early Grade Reading Assessment. (2010). "Early Grade Reading Assessment: Ethiopian - Data Analytic Report: Language and Early Learning" Addis Ababa, Ethiopia.

[5] Brown, H.D. (1994). Principles of Language Learning and Teaching. The USA: Prentice Hall Regents

[6] Cunnings worth, A. (1995).Choosing Your Course Book. London: Heinemann.

[7] Federal Democratic Government of Ethiopia. (1994). Education and Training Policy.

[8] Getinet Ayalew. (2018). Evaluating the Appropriateness of Grade 9 English Reading Texts: From the Perspective of Teacher and Students. Unpublished MA Thesis .Debre Markos University.

[9] Institute for curriculum Develop and Research Inst /Ethiopian Ministry of Education. (2004). Syllabus for Grade Seven English (Revised). Addis Ababa University Press: Addis Ababa.

[10] Judy L. N. (2007). An exploration of the impact of picture book illustration on the Comprehension skills and vocabulary Development of Emergent Readers (Dissertation) Louisiana State University: Baton Rouge.

[11] Jordan, R.R. (1997). English for Academic Purposes: A Guide and Resource Book for Teachers.New York: Cambridge University Press. 
[12] Kirkgoz, Y. (2009) "Evaluating the English Textbooks for Young Learners of English at Turkish Primary ducation" Procedia Social and Behavioral Sciences , 1, 79-83.

[13] Ling, Y.C., Tong, C.S. \& Jin, N.Y. (2012). Evaluating the ESL Reading Texts for Intermediate Learners of English from the Perspective of Students. Global Journal of Human Social Science, 12(7), 54-60.

[14] Lyon, G. R. (2003). 'Reading Disability: Why Do Some Children Have Difficulty Learning? National Institutes of Health, Bethesda.

[15] Md. Hamidurn Rahman. (2004). An Evaluation of the Teaching of Rreading Skills of English in Bangladesh. University of Rajshahi ,Bangladesh.

[16] Ministry of Education. (2007). Study on Medium of Instruction in Primary Schools in Ethiopia: Final Report Document .Federal Democratic Republic of Ethiopia, Addis Ababa.

[17] Niederhauser, J.S. (1997). "Motivating Learners at South Korean Universities.” English Teaching Forum 35(1), 8-11.

[18] Raval, G.P. (2013). Critical analysis of English (second language) Textbook of Standard Vii. International Journal of Research in Humanity and Social Science.1 (9), 6-9.

[19] Sheldon, L.E. (1988). Evaluating ELT Textbooks and Materials. ELT Journal, 42. (4), 237-246.

[20] Ur, P. (1996). A Course in Language Teaching. Cambridge: Cambridge University Press

[21] Williams, R. (1986). “Top Ten Principles for Teaching Reading.” ELT Journal Vol 40 (1) , $42-45$

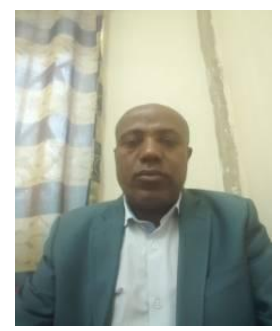

Simachew Gashaye was born at Debre Markos, in 1974. He has completed his BA degree in Education at Bahir Dar University, Ethiopia in 2000. He has received his MA degree in Teaching English as Foreign Language (TEFL) from Addis Ababa University, Ethiopia, in 2005. He has also received his PhD in TEFL from the same University in 2012.

With his field of study, he is offering MA courses in TEFL and supervising the students at Debre Markos University, Ethiopia. In addition, he has served the University as Vice President for Research and Community Service (2013-2017), as Director for Continuing Education (2007-2009), Board Member of the University Business Enterprise and as member of Senate Standing Committees of the University.

Currently, he is engaged in research undertakings after serving the University in different positions. His research interest area is in language teaching especially language testing. He has been publishing articles. To mention some journals, International Journal of Current Research Volume 9(12), 9106 - 9111, December 2019; Indus Foundation for Research and Social Welfare, 9(11), 41-50, November 2019; Journal of Education and Practice, 10 (22), 23-40, August 2019.

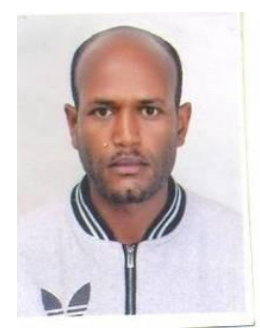

Manyazewal Girma was born in Oromiya Regional State at Addis Alem District, Ethiopia, in 1988. He attended his BA degree in teaching at Ambo University, Ethiopia and graduated in 2014. He has received his MA degree in TEFL from Debre Markos University, Ethiopia, in 2019. Currently, he is teaching English Language in Secondary Schools, in Addis Ababa, Ethiopia. 